sekerusd@gmail.com

\title{
ANALIZA PROBLEMA U PREVOĐENJU SA KINESKOG NA ENGLESKI NATPISA U JAVNOM PROSTORU ${ }^{1}$
}

SAŽETAK: Ulice kineskih gradova danas su pune natpisa na engleskom jeziku, uputstava, reklama i informacija namenjenih strancima, prevedenih sa kineskog. Međutim taj engleski jezik je daleko od engleskog jezičkog standarda. Tu činjenicu zapazili su mnogi turisti i stranci koji žive u Kini, koji obavezno fotografišu bar jedan takav natpis na „smešnom engleskom“. Rad je pokušaj analize i uzroka grešaka koje nastaju u prevođenju natpisa u javnom prostoru sa kineskog na engleski. Pored velikih razlika u karakteristikama dva jezika, nedostatak stručnih prevodilaca i prekomerna upotreba softvera za prevođenje, koju ne prati stručna redakcija prevoda, još je jedno od objašnjenja ove pojave. Uostalom, mnogi od natpisa na engleskom jeziku u javnom prostoru $u$ Kini i nisu namenjeni strancima, već „komuniciraju“ sa lokalnim stanovništvom i imaju više dekorativni nego informativni karakter jer stvaraju privid internacionalizacije.

Ključne reči: kineski jezik, engleski jezik, mašinski prevod, javni prostor

\section{UVOD}

Tokom boravka u Kini, gde sam studirala kineski jezik i kulturu, primetila sam da pored kineskog u javnom prostoru postoje mnogi natpisi na lošem engleskom jeziku. U pitanju su natpisi koji se nalaze u metroima, hotelima, restoranima, bolnicama, robnim kućama, parkovima, muzejima, na odevnim predmetima. Taj fenomen je veoma prisutan i u virtuelnom prostoru, u objavama na društvenim mrežama. Kako sam sve više napredovala u kineskom jeziku, i imala bolji uvid u kinesku kulturu i mentalitet, počela sam da tragam za mogućim objašnjenjima te pojave. U istraživanju za ovaj rad shvatila sam da ima malo stručnih i naučnih radova koji obrađuju ovu temu. Rad predstavlja skromni doprinos analizi uzroka grešaka $u$ prevođenju sa kineskog na engleski $u$ svakodnevnom životu.

\footnotetext{
${ }^{1}$ Rad je nastao na masterskim studijama Jezik, književnost, kultura Filološkog fakulteta Univerziteta u Beogradu, na predmetu Translatologija, pod mentorstvom doc. dr Mirjane Daničić.
} 


\section{KRATAK PREGLED KARAKTERISTIKA KINESKOG JEZIKA}

Jedna od bitnih razlika između kineskog i evropskih jezika je pismo. Kinezi u svakodnevnom životu koriste oko šest do osam hiljada karaktera, dok se u kineskim rečnicima može pronaći i preko 20.000 karaktera. U kineskom jeziku, za razliku od evropskih jezika, reči imaju jedan izvorni oblik i taj se oblik ne menja u zavisnosti od funkcije u rečenici. Nema različitih glagolskih oblika niti konjugacije. Imenice i pridevi nemaju rodove i brojeve, niti se menjaju po padežima. Po kineskoj gramatici, reč ostaje uvek u istom obliku. Za prikaz roda, broja, vremena, čak i emocija, u rečenicama se koriste različiti prefiksi i sufiksi. Takođe, u kineskom pismu između reči nema razmaka, i često nije jasno gde je kraj jedne reči a gde početak druge.

Kada je reč o znakovnim karakterima u kineskom pismu, jedan karakter može biti cela reč, ili slog. Većina karaktera ima jedno značenje (neki imaju dva i više), ali u kombinaciji sa drugim karakterima stvaraju potpuno novu reč. $\mathrm{Na}$ primer, karakter , 花“( $(h u \bar{a}){ }^{2}{ }^{2}$ kao imenica, može da znači ,cvet“, ali može da bude i glagol i tada znači ,potrošiti“. U kombinaciji sa karakterom „,生“ (shēng), koji kao imenica znači „rađanje“, „život", a može da bude i pridev sa značenjem „sirovo“, „花生“ (huāshēng) ne daje ništa poput, manje više očekivanog, „,cvet roditi“ ili ,potrošiti sirovo“, već stvara potpuno novu reč - „kikiriki“.

Zbog ovih i mnogih drugih specifičnosti kineskog jezika, ali i zbog nedovoljnog poznavanja bogate kineske kulture, kao i nedostatka dovoljno stručnih prevodilaca, vrlo lako dolazi do grešaka u prevođenju.

\section{PRIMERI PROBLEMATIČNIH PREVODA SA KINESKOG NA ENGLESKI I NJIHOVA ANALIZA}

Za potrebe ovog rada, odabrano je nekoliko primera koji mogu biti reprezentativni uzorak za ilustraciju problema u prevođenju sa kineskog na engleski u svakodnevnom životu.

\footnotetext{
${ }^{2} \mathrm{U}$ zagradama će biti naveden izgovor kineskih karaktera, napisan u pinjinu. Pinjin je zvanična alfabetizacija kineskih karaktera koja se koristi za pomoć u učenju kineskog. Pinjin je jedna vrsta fonetske transkripcije.
} 


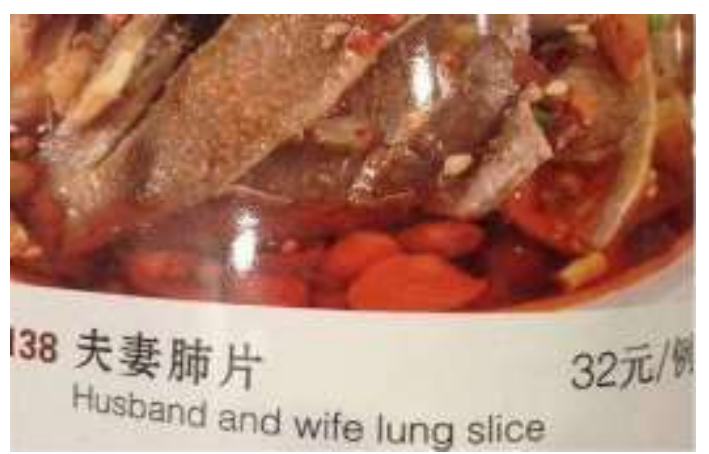

Fotografija 1: https://www.actranslation.com/knowledge/fun/hilarioustranslations.htm

Prvi primer koji će se analizirati je naziv jela „夫妻肺片“(fūqū fèipiàn), koje često u restoranima, u meniju, možemo naći pod engleskim nazivom Husband and wife lung slice (Muž i žena parče pluća). Ovaj bukvalan prevod je zapravo donekle tačan, u slučaju da prevodilac nije znao da prevodi meni za restoran. Suočavamo se sa neadekvatnim prevodom nastalim zbog nepoznavanja kineske kulture.

Naime, tokom Ćing dinastije, na ulicama tadašnje Kine, bilo je mnogo uličnih prodavaca jela pripremljenih od iznutrica, mahom goveđih, jer su bile relativno jeftine. Ta su jela služena hladna, sa ljutim sosom. U tridesetim godinama dvadesetog veka, jedan bračni par iz grada Čengdu, u provinciji Sečuan, postaje poznat po svojoj varijaciji ovog jela. Do tada, jelo nije imalo određeno ime, već se naručivalo kao „mešana hladna govedina sa sosom“. Ovaj bračni par je popularizovao to jelo i gosti su ga prozvali , 夫妻废片“ (fūqū fèipiàn), što u bukvalnom prevodu znači Husband and wife offal slices (Muž i žena komadi iznutrice).

Interesantno je da prvobitni naziv jela ima u sebi karakter ,废“ (fèi) tj. „iznutrice“, ali je on zamenjen karakterom „肺“ (fèi) što znači „pluća“, koji se pritom isto izgovara, kako bi ime jela zvučalo i izgledalo manje odbojno. Legenda kaže (https://languagelog.ldc.upenn.edu), da je izvesni trgovac koji je probao njihov specijalitet, bio toliko oduševljen, da im je izradio ploču od zlata na kojoj je pisalo ,夫妻肺片“ fūqū fèipiàn, (muž i žena parče pluća) i od tada je ostao taj 
naziv za jelo. Iako se danas pravi od goveđeg mesa, srca, jezika i tripica, ${ }^{3}$ a ne pluća, ime je ostalo nepromenjeno. Bolji prevod na engleski bi bio Sichuan beef slices in chilli oil (Seckana govedina u čili ulju na sečuanski način).

Sledeći primer je idiom „人山人海“ (rén shān rén hăi) koji nalazimo preveden kao „People mountain people sea“ (Ljudi planina ljudi more). To je jedan od najpoznatijih kineskih idioma i jedan od prvih koji se pominju tokom učenja jezika. Karakter „人“ (rén) znači „,̌ovek“ ili „ljudi“, iliti people na engleskom. Karakter „山“ (shān) predstavlja planinu tj. mountain, a karakter „海“ (hăi) ,more“, odnosno sea. Dakle, vidimo da je idiom doslovno preveden, reč po reč, po čemu se može zaključiti da je preveden pomoću nekog softvera za prevođenje, koji je koristio nestručni prevodilac i izvorni govornik kineskog jezika, koji verovatno nije uspeo da pronađe adekvatan idiom u engleskom jeziku, niti se zapitao da li People mountain people sea znači nešto na engleskom. Manje je verovatno da je prevodilac stranac, koji je početnik u učenju kineskog jezika, jer kao što je prethodno navedeno, ovo je jedan od najrasprostranjenijih i najviše korišćenih idioma.

Pravilan prevod ovog idioma bi bio „mnoštvo ljudi“ ili „more ljudi“, tj. packed with people, a sea of people, i koristi se u opisivanju situacija u kojima je velika gužva, tokom nekog većeg događaja i slično. Najčešće se čuje na turističkim mestima u Kini, tokom kineskih praznika, kada pejzaž zaista postaje People mountain people sea.

Ovaj izraz, sada opšte prihvaćen sa notom humora i ironije, nalazi se i u Urbanom rečniku (urbandictionary.com), sa definicijom: It means there are a lot of people in some place, very crowded. Usually used to describe a big event, a scene. (Znači da na jednom mestu ima puno ljudi i da je gužva. Obično se koristi da opiše veliki događaj ili scenu).

\footnotetext{
${ }^{3}$ Reč francuskog porekla (tripes), jelo koje se pravi od očišćenih želudaca različitih životinja.
} 


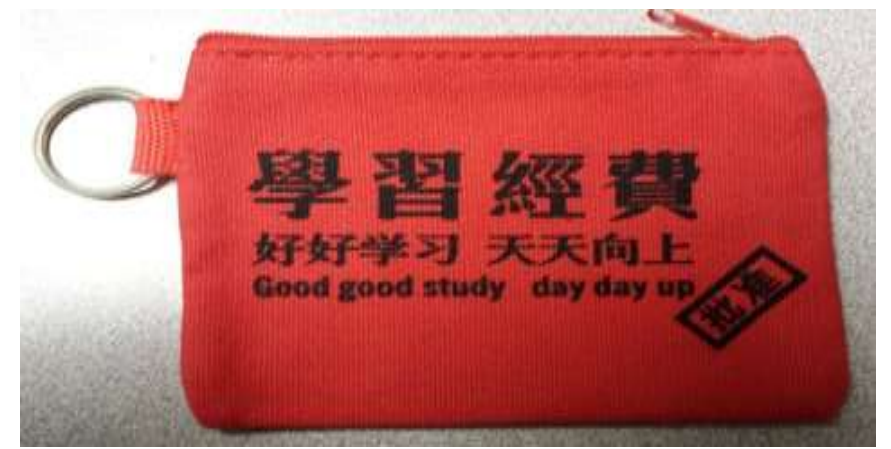

Fotografija 2. https://languagelog.ldc.upenn.edu/nll/?p=9686

Sledeći primer je ,好好学习, 天天向上“ (hăohăo xuéxí, tiāntiān xiàngshàng) što je prevedeno kao Good good study, day day up. Izreka se pripisuje bivšem kineskom predsedniku, Mao Cedungu i trebalo bi je prevesti kao Study (work) hard, improve daily. Koristi se kad ohrabrujete nekog ko počinje da uči nešto novo. Ponavljanje karaktera u kineskom prevedeno je kao ponavljanje reči u engleskom, ali takvim postupkom nije ostvaren željeni smisao.

U kineskom jeziku neki pridevi i predlozi, kako bi im se pojačalo značenje, mogu da se dupliraju, kao što je slučaj sa „好“ (hăo), čije je najčešće pridevsko značenje ,good“ tj. „dobro“. U ovom slučaju, dupliran, ima formu priloga well ili properly, ispred glagola, „学习“ (xuéxí), to study tj. „učiti“. Sa druge strane, neke duplirane imenice, poput „天“( $(t i \bar{a} n)$, koja ovde predstavlja „dan“ iliti day, ukazuju na to da se radi o svakodnevnom zbivanju, u ovom slučaju „svaki dan“ tj. every day. Glagol „向上“ (xiàngshàng) u doslovnom prevodu znači to go up, ali takođe ima značenje to make progress.

Problem je verovatno nastao mašinskim prevođenjem, kad prevodilački alati nisu bili sofisticirani kao danas, jer je bukvalno prevođenje ,reč po reč“ jedna od karakteristika mašinskog prevođenja. Ako bismo danas proverili prevod uz pomoć alata Google translate, dobili bismo tačan prevod.

Ova dva „pogrešna prevoda“ (People mountain people sea; Good good study, day day up) na neki način su već postali kultni. Postoje blogovi i televizijske emisije u Kini pod nazivom 天天向上 Day day up (https://en.wikipedia.org/wiki/Day_Day_Up), pa se postavlja pitanje da li se i danas ovde greši u prevodu (što je malo verovatno, pošto nove alatke za prevod daju tačan prevod), ili je Good good study, day day up postao ustaljena i 
opšteprihvaćena forma prevoda koja je iz nekog razloga kineskoj publici interesantna i zabavna.
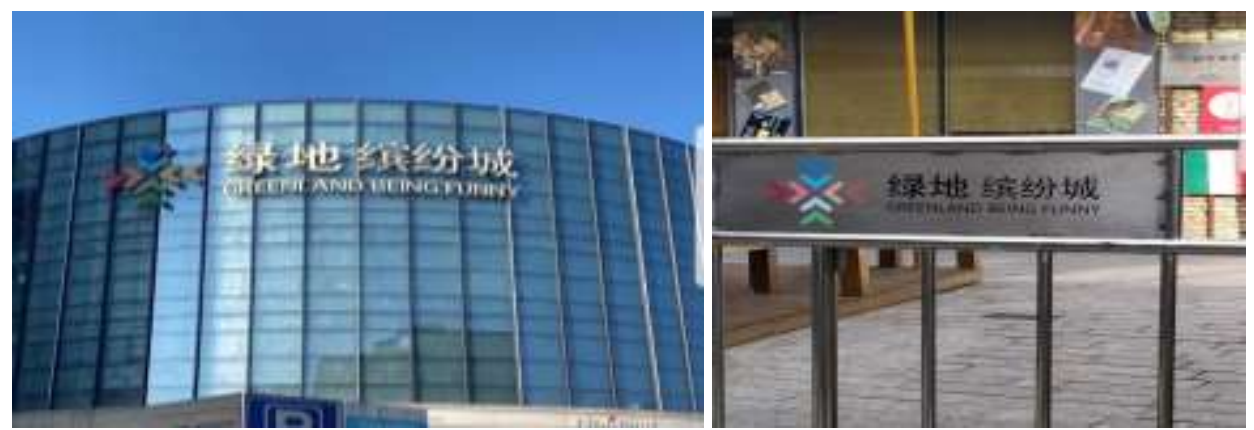

Fotografije 3 i 4: u Šangaju 15. 08. 2019.

Na zgradi i kapiji ovog tržnog centra u Šangaju nalazi se veliki natpis naziva tržnog centra na kineskom, , 绿地缤纷城“ (lüdì bìnfênchéng) i na engleskom Greenland being funny.

Karakteri „绿地“ (lù̀di) na kineskom imaju značenje Green space ili Green area, poput parka ili bašte. Treba uzeti u obzir da se ovde zaista radi o „zelenom“ ili „ekološkom“ tržnom centru, sa puno zelenih površina i baštom na krovu, te stoga i jeste donekle Greenland. Karakteri „缤纷“ (binfēn) se prevode kao colourful, ,šaren“, i često ih povezujemo sa zabavom, radošću i srećom, tako da bi u slobodnijem prevodu moglo da se upotrebi i značenje fun na engleskom. Karakter ,城“ (chéng) označava reč city tj. „grad“.

Do problema je došlo u interpretaciji karaktera „缤纷“ (bīnfēn), iliti na engleskom colourful. Postoji mogućnost da je prevodilac bez konsultovanja rečnika odlučio da ,缤纷“ (binfēn) znači being funny, (postoji čak i delimično fonetsko poklapanje), kao i mogućnost da je smatrao da je umesto „缤纷“ (bìnfēn) bolje staviti reč , ,好玩“ (hăowán), što može imati značenje fun, amusing i da je na taj način došlo do prevoda being funny, netačnog i komičnog.

Ovde je možda interesantno spomenuti da i Francuzi često prave grešku u govoru kada koriste reči fun i funny kao sinonime, jer u francuskom drôle znači da je nešto „smešno“, ali u slengu može značiti i da je npr. neki događaj bio „zabavan“. 
Bolji prevod za naziv ovog tržnog centra bi bio Greenland fun city ili Greenland colourful city.

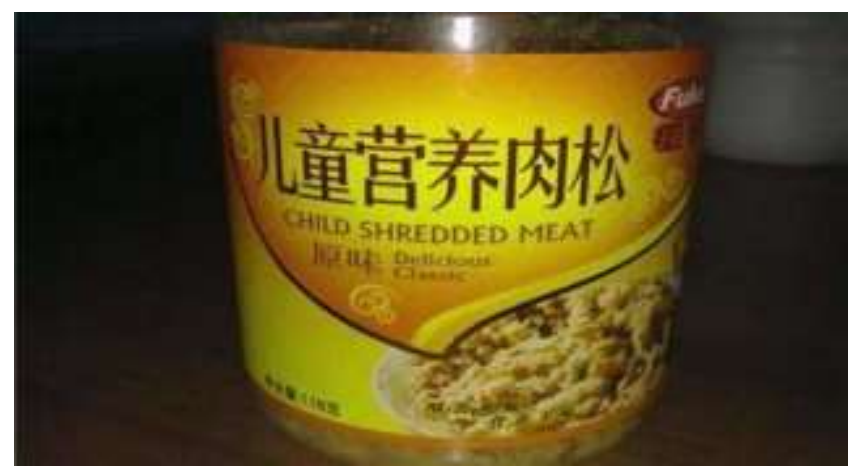

Fotografija 5: https://www.actranslation.com/knowledge/fun/hilarioustranslations.htm

U sledećem primeru, nailazimo na teglu nečega što se zove Child shredded meat (Dečije sitno seckano meso), odnosno na kineskom ”儿童营养肉松“ (értóng yíngyăng ròusōng). Karakteri „儿童“ (értóng) znače child, dok karakteri ,营养“ (yíngyăng) imaju značenje nutritious, a karakteri „肉松“ (ròusōng) znače meat floss (mesni končići) iliti shredded meat (sitno seckano meso). Kada prevedemo reč po reč, shvatamo da je problem u prevodu došao verovatno zbog mašinskog prevođenja i zbog redosleda reči u rečenici na kineskom jeziku. Do greške je najverovatnije došlo jer se u kineskom nazivu podrazumeva da je proizvod namenjen deci, i naravno nema predloga „for“ na kineskom koji bi verovatno olakšao prevod mašini za prevođenje.

Dobar prevod bi glasio Shredded meat for children (Sitno seckano meso za decu), Nutritious meat floss for children (Hranljivi mesni končići za decu) ili Pulled pork for children (Cepkana svinjetina za decu), u zavisnosti od vrste mesa koje se koristi, jer se radi o hrani za bebe i malu decu, a ne o hrani napravljenoj od istih. 


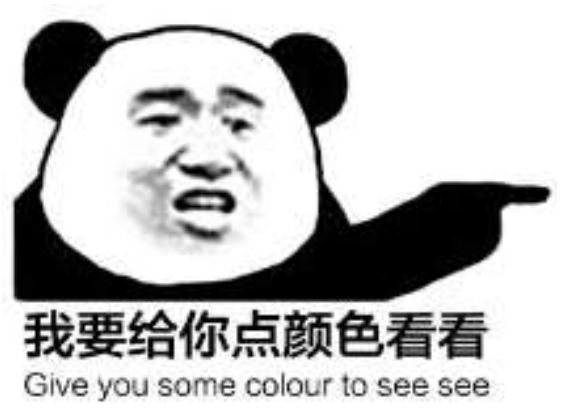

Fotografija 6: http://www.bqb12.com/biaoqing/116196

Kinesku kolokvijalnu frazu ,我要给你点颜色看看“ (wŏ yào gěi nŭ diăn yán sè kàn kan) danas u nekim prevodima filmova nalazimo prevedenu na engleski kao Give you some colour to see see. Ovde je reč o doslovnom, ili mašinskom prevodu. Prevod svake reči je tačan, ali značenje ove fraze je potpuno drugačije. , 我要给你点颜色看看“ (wŏ yào gěi nǐ diăn yán sè kàn kan) bi trebalo prevesti kao I will teach you a lesson (Naučiću te ja pameti) ili I will put you in your place (Šta ti misliš ko si?) i koristi se u situacijama u kojima se preti nekoj osobi, a boja koja se spominje je, vrlo verovatno, boja modrice na telu.

Interesantno je što ovde vidimo jednu od specifičnosti kineskog jezika, a to je dupliranje glagola „, 看“ (kàn), ,videti“, na kraju rečenice. Dupliranje glagola se koristi kada želimo da prikažemo da je radnja kratkog trajanja ili smanjenog intenziteta (https://www.chinese-grammar.org). Ako je neko prevodilac i prevodi sa kineskog jezika, makar i početnik, i ima osnovno znanje engleskog jezika, zna za pravilo dupliranja glagola u kineskom, kao i da isto pravilo ne važi $u$ engleskom. Stoga zaključujemo da ovo može biti samo mašinski prevod.

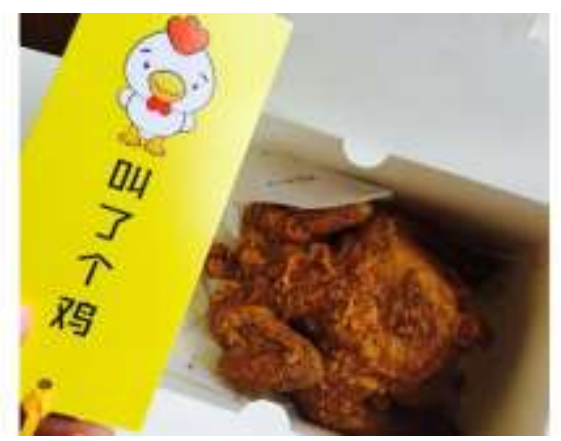

Fotografija 7: Slikala autorka u Šangaju 2016. godine. 


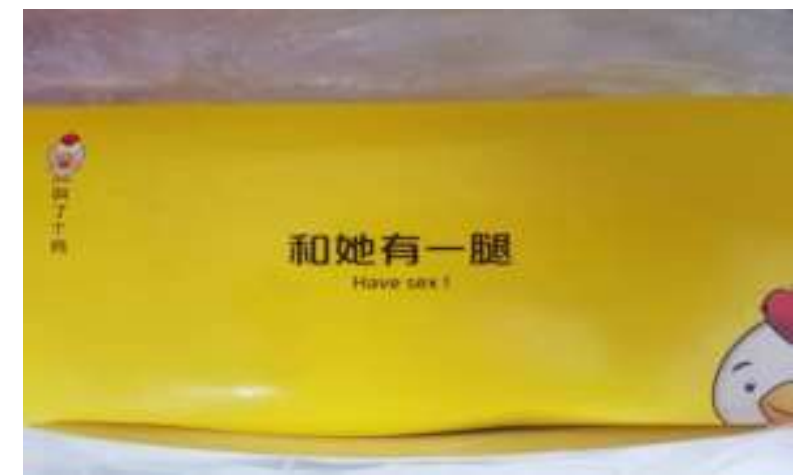

Fotografija 8: http://www.jiaolgeji.com/zixun/6541.html

Sledeći primer (fotografije 7 i 8 ) je zaista veoma neobičan prevod, skoro

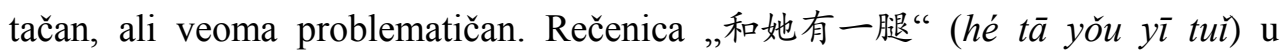
bukvalnom prevodu znači „sa njom imati nogu“, ali je prevedeno kao Have sex! Ovaj interesantan natpis pronašla sam na ambalaži iz kioska brze hrane, pored mog bivšeg univerziteta u Šangaju, koji prodaje isključivo pohovane pileće batake. Restorančić se zove „叫了个鸡“ (jiàole gè jī). U njegovom nazivu se radi o igri reči i upečatljivom marketingu, koji nažalost preveden na engleski, na ovaj način, može samo da zbunjuje, iako ostaje u pamćenju.

Za početak, kao što sam rekla, ime kioska , 叫了个鸡“ (jiàole gè jī), već po sebi je igra reči. Doslovno prevedeno znači ,pozvati kokošku“, što donekle ima smisla, jer se radi o pečenoj piletini, pa bi moglo da implicira na dostavu pečene piletine. Pravo značenje je u stvari „pozvati prostitutku“. Karakter „,鸡“ ( $j \vec{\imath})$ na kineskom označava kokošku, a karakteri ,妓女“ (jì nü), ili skraćeno samo karakter „妓“ (jì), tvore reč koja potiče iz kantonskog jezika i u slengu označava prostitutku (A Dictionary of Hong Kong English, 2011: 30). Na predavanju iz predmeta Kultura kineskih karaktera, profesor Vu Jen Vej (吴延伟), sa Donghua univerziteta, objasnio nam je da su u Hong Kongu nekada devojke koje su plesale na bini i zabavljale publiku, pravile kostime od perja, te odatle verovatno dolazi spontana zamena značenja reči „鸡“ (jj) sa rečju ,妓“ (ji), koje su slične i po zvučnosti.

Što se tiče prevoda ,和她有一腿“ (hé tā yǒu ȳ tul̆) sa kutije, pravo značenje je „imati ljubavnu aferu“. Zašto „sa njom imati nogu“ znači „imati aferu“? Jedno moguće objašnjenje je da su afere i preljube, u većini slučajeva tajne stvari, što znači da se moraju obaviti skriveno i efikasno, što ne daje vremena da se 
skinu cele pantalone, već samo jedna nogavica. Iz ovog objašnjenja dolazimo do „imati jednu nogu“.

Da li je zaista došlo do greške u prevodu jer prevodilac nije znao da Have sex! na kutiji sa piletinom, bez poznavanja kineskog jezika i igre reči, neće imati nikakvog smisla, ili je i sam prevod marketinški trik, ne znamo. Znamo samo da je ovaj lanac kioska postao veoma popularan širom Kine i puno se pričalo o njemu, baš zbog imena.

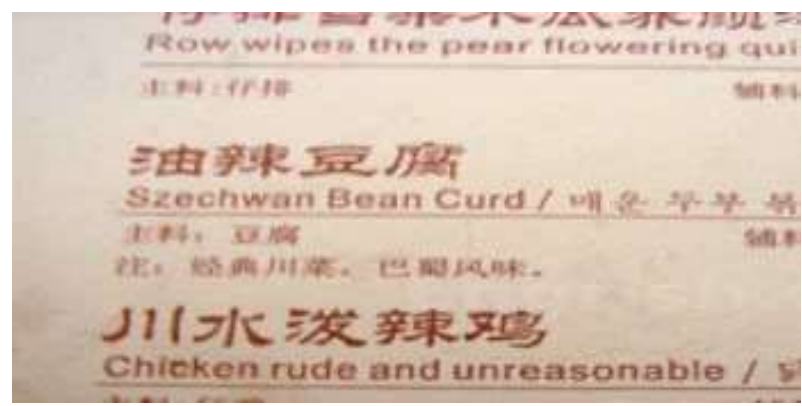

Fotografija 9: https://www.actranslation.com/knowledge/fun/hilarioustranslations.htm

Naredni primer (fotografija 9) koji sam odabrala je jedan od poznatijih koji cirkulišu internetom. Jelo,„川水泼辣鸡“ (chuānshuǐ pōlà jī) možete naručiti u ovom restoranu kao Chicken rude and unreasonable (Nepristojna i nerazumna piletina).

Ovo čuveno sečuansko jelo, koje je trebalo da bude prevedeno kao Sichuan style spicy chicken (Ljuta piletina na sečuanski način) na engleski je prevedeno mašinski, verovatno pre više od nekoliko godina, jer danas, kad ukucamo ime ovog jela u neki od novijih alata za prevođenje, dobijamo tačan prevod koji glasi Sichuan spicy chicken.

Problem je nastao kod karaktera, ,泼辣“ (pōlà), koji u slengu znače „nepristojno“, ili ako koristimo kineski softver za prevođenje, „Baidu“ (nešto slično kao Google translate), dobijamo značenje rude and unreasonable (nepristojno i nerazumno).

Sam karakter „泼“ ( $p \bar{o})$ znači „posuti“, a karakter „辣“ (là) označava „ljuto“, međutim, kada stoje zajedno i predstavljaju jednu reč, dobijamo potpuno novu reč „nepristojno“, koja nema veze sa istim karakterima kada stoje sami, i tako dolazi do prevoda Chicken rude and unreasonable. 


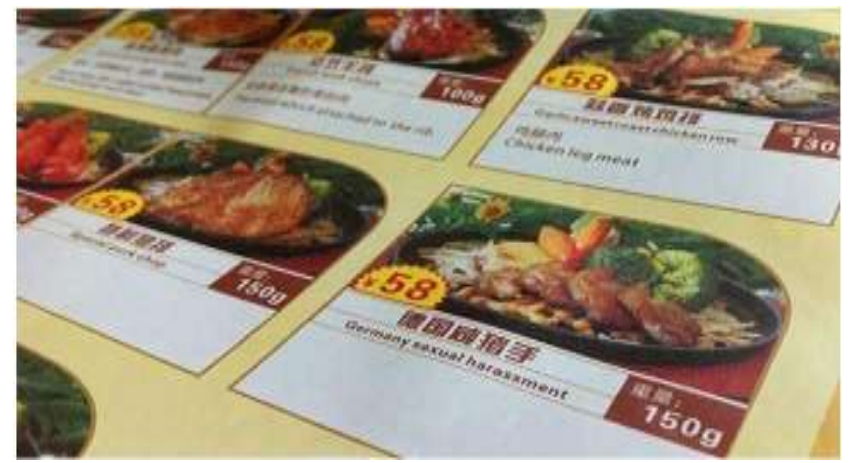

Fotografija 10: https://www.actranslation.com/knowledge/fun/hilarioustranslations.htm

Germany sexual harassment (Nemačka seksualno uznemiravanje) je jedno od jela koje možete poručiti u restoranu u čijem je ovaj meni fotografisan. Kineski naziv je ,德国咸猪手“ (déguó xián zhūshǒu). Karakteri ,德国“ (déguó) označavaju državu Nemačku, karakter „咸“ (xián) znači „slano“, a karakteri „猪手“ (zhüshǒu) znače „svinjska noga“, tako da bi pravilan prevod glasio German style salted pork knuckle.

Kako je došlo do ovako velike greške? Problem nastaje očiglednim mašinskim prevođenjem. Prvi deo, „Nemačka“ je dobro preveden, ali „slana svinjska noga“ iliti „咸猪手“ (xián zhūshǒu) kao jedna cela reč, a ne odvojeno „slano“ + „svinjska noga“, ima još jedno značenje. Sleng koji potiče iz Hong Konga i Makaoa, ,咸猪手“ (xián zhūshǒu) u stvari znači wandering hands, tj. „ruke koje lutaju“ - rečeno na finiji način (https://baike.baidu.com).

Ovde se radi o prevodiocu koji nema nikakvo znanje engleskog jezika, koji je koristio softver za prevođenje i stoga je došlo do ovog problematičnog prevoda. Takođe, vrlo je moguće da je ovo restoran koji se nalazi baš u Hong Kongu. 


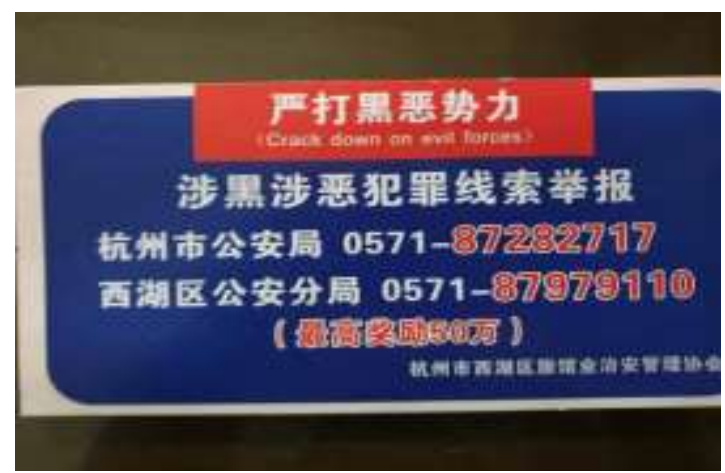

Fotografija 11: Slikala autorka u hotelu Šeraton u Hangdžou 2018. godine.

Sledeći primer je upozorenje gostima hotela, fotografisano u hotelskom lobiju, u gradu Hangdžou. Rečenica na kineskom glasi ,严打黑恶势力“ (yándă hèi è shili), a u engleskom prevodu Crack down on evil forces (Suzbi zle sile). Prva pomisao je bila da se radi o nekim „magičnim“ silama, ali nakon pažljivijeg pregleda kineskih karaktera i drugog dela informacije i brojeva telefona policijskih lokalnih stanica, shvata se da se radi o obaveštenju policije.

Naime, problem nastaje zbog karaktera, ,恶“ (’̀), koji može predstavljati imenicu evil, ali i crime. Karakteri ,黑恶势力“ (hēi è shili) predstavljaju evil forces, ali u smislu „ljudi iz podzemnog, tj. kriminalnog sveta“, a ta je greška nastala najverovatnije zbog mašinskog prevoda ili lošeg izbora značenja reči $u$ rečniku. Karaktere,,黑恶势力“ (hêei è shili) bismo, dakle, mogli da prevedemo kao „kriminalne organizacije“.

Karakteri „严打“ (yándă) imaju značenje to crack down on..., kao i to take severe measures against... (preduzeti stroge mere protiv...), i često se koriste kada je reč o kriminalu i zakonskim kaznama. Bolji prevod bi možda bio Crack down on crime.

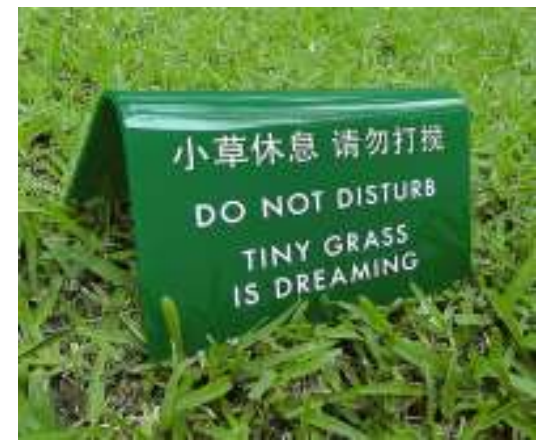

Fotografija 12: https://languagelog.ldc.upenn.edu/nll/?p=3978 
Drugi primer, fotografija 12 table koja se nalazi na travnjaku u parku, nije izabran kao pogrešan prevod, jer je prevod sa kineskog na engleski manje-više dobar. Nekome ko se prvi put susreće sa sličnim natpisom, poruka može biti potpuno nejasna. U duhu kineskog jezika, koji je vrlo poetičan, susrećemo se sa idejom da trava može da „sanja“, u ovom slučaju sveže posađena trava iliti tiny grass, „sanja“ da poraste. U kineskom jeziku, metafore i idiomi se obilato koriste u svakodnevnom životu i imaju bitne uloge u govoru. Uz pomoć idioma i metafora stičemo uvid u kulturu i način razmišljanja određenog naroda, u ovom slučaju kineskog. Ova metafora, da „trava sanja“, korišćena je da bi poruka izazivala emotivnu reakciju kod većeg broja ljudi i da bi delovala na neki način „slađe“, i time verovatno imala više šanse da zapravo spreči nekog da gazi po travi.

Nažalost, ovakve metafore iz kineskog jezika kada se bukvalno prevedu deluju kao da je prevodilac potpuno ,promašio“ prevod ili kao da je jednostavno poludeo, a kod stranaca najčešće izazivaju smeh. Ovde bi tačan prevod bio jednostavno: Keep off the grass (Ne gazi travu).

\section{ISTORIJSKA I SOCIOLOŠKA USLOVLJENOST PREVODA}

Engleski jezik počeo je da se koristi u Kini u XIX veku, zahvaljujući trgovačkim vezama, pre svega sa Velikom Britanijom. Kasnije, sve do osnivanja Narodne Republike Kine sredinom XX veka (proglašena 1. oktobra 1949. godine), engleski jezik su u Kini predavali zapadni misionari. Nije bilo prave strategije $\mathrm{i}$ politike učenja stranih jezika. Postepeno, a naročito kako se krajem XX veka NR Kina otvarala prema svetu, intenzivira se upotreba engleskog jezika u međunarodnim odnosima, ekonomiji i obrazovanju (Zhang, 2008). Engleski je postao najvažniji strani jezik u školama i jedan je od obaveznih predmeta na nacionalnoj maturi od 1982. godine (Hui, 2001). Danas svaki fakultet, bez obzira koji je studijski program u pitanju, mora da ima kurs pod nazivom College English in China koji je obavezan za sve studente. Procene su da danas preko 300.000.000 Kineza čita i piše engleski, ali nemaju dovoljno prakse i mogućnosti da ga usavršavaju.

Pošto je potražnja za profesorima engleskog u Kini neprekidna, zbog ogromnog broja zainteresovanih da ga uče, danas ima mnogo nekvalifikovanih profesora kojima engleski nije maternji jezik, niti su se obučavali da predaju engleski kao strani jezik. Ti isti ljudi su često angažovani da prevode ili rediguju prevode, bez proveravanja njihove sposobnosti i kvalifikacija, što može da bude jedan od razloga za toliko neobičnih prevoda u javnom prostoru. 
Kako Kina postaje svetska ekonomska i politička sila, sve više Kineza uči engleski jezik, ali takođe sve više ljudi zapaža nedostatke tog engleskog jezika koji se čita i piše u Kini. Zbog toga su kineska Državna komisija za jezik i Ministarstvo obrazovanja NR Kine zajedno pripremili dokument pod nazivom „Novi nacionalni standardi za upotrebu engleskog jezika“ (The new national standards on use of English). U tekstu koji sadrži 13 poglavlja među kojima su i obrazovanje, turizam, transport, finansije, hotelijerstvo, nalaze se i ,tačni prevodi““ za najčešće upotrebljavane reči u ovim oblastima. U planu je da se prevede oko 3500 natpisa sa najfrekventnijim frazama i natpisima, takođe predviđeno je i da se zabrani upotreba prevoda koji bi mogli da štete ugledu Kine.

Ovo je bila zvanična reakcija NR Kine posle Letnjih olimpijskih igara u Pekingu 2008. godine, kada je turistički biro otvorio telefonsku liniju, da bi im se dojavljivalo gde ima loših prevoda. Slični pokušaji su bili i u Šangaju 2010. godine, pre Svetske izložbe (Byrne, 2017).

Poznavanje jezika ne može da bude odvojeno od poznavanja kulture, istorije, konteksta, emocionalne ili simboličke vrednosti upotrebe jezika. Možda će za neupućene zvučati čudno, ali u mnogo slučajeva, natpisi na engleskom jeziku u Kini uopšte i nisu namenjeni strancima. Tekst ispisan na engleskom često ima samo „dekorativnu“ funkciju, on obeležava neko mesto (bar, restoran, hotel, kafe) ili neki odevni predmet. Ciljna grupa kojoj su natpisi namenjeni je lokalno stanovništvo koje na taj način prividno „konzumira“ nešto internacionalno, što je znak prestiža i poželjni statusni simbol.

Takođe, ekonomski razlozi mogu biti u korenu površnog odnosa prema prevođenju. U Kini su brzina i efikasnost urađenog posla, kao i najniža cena koja odlučuje ko će dobiti posao, važniji od temeljne provere kvaliteta, a kvalitet prevoda (osim u izuzetnim slučajevima) nije prioritet poslodavaca.

Iz tih razloga se najčešće koriste prevodilački alati, koje koriste ljudi koji čak ne moraju da znaju engleski, što je najčešće i slučaj. U Kini je tehnologija vrlo razvijena, svima su dostupni pametni telefoni sa bezbroj aplikacija za prevođenje. To je u širokoj upotrebi u tolikoj meri, da svi imaju iluziju da mogu da budu prevodioci, da je to lak posao i da za to ne treba ulagati puno novca, jer već postoje aplikacije koje obavljaju posao umesto ljudi.

Današnji prevodilački alati su napredniji nego što su nekada bili, pogotovo kada se prevode kratke i jednostavne rečenice, ali i dalje prevodi idioma, 
kompleksnijih rečenica i slenga ne mogu biti dobro prevedeni bez intervencije stručne osobe - kvalifikovanog prevodioca.

\section{ZAKLJUČNA RAZMATRANJA}

Nakon obavljenog istraživanja, došlo se do zaključka šta bi sve mogli biti razlozi za probleme u prevođenju sa kineskog na engleski u svakodnevnom životu. Pre svega, u pitanju su specifična gramatička pravila kineskog jezika, koja su navedena na početku rada, kao i sama priroda kineskog jezika koji je vrlo poetičan, što možda najbolje ilustruje primer sa „malom travom koja sanja da poraste“.

Takođe, nedostatak stručnih prevodilaca i prekomerna upotreba softvera za prevođenje, nakon kojih gotovo redovno izostaje stručna redakcija prevoda, još je jedan od razloga za problematične prevode.

Mnogi od natpisa na engleskom jeziku u javnom prostoru u Kini i nisu namenjeni strancima, već „komuniciraju“ sa lokalnim stanovništvom i imaju više dekorativni nego informativni karakter. Tekst na engleskom jeziku je signal izlaska Kine na međunarodnu scenu, poruka stanovništvu da su deo globalnog sveta i da prate internacionalne trendove (svakako bi poseban rad mogao da se posveti neverovatnim i neprimerenim sloganima na engleskom jeziku, koji se nalaze na majicama koje Kinezi svih uzrasta nose, bez kompleksa i bez znanja šta ti natpisi zaista znače).

$\mathrm{Na}$ kraju, zbog toga što kineski poslodavci, vođeni ekonomskom logikom, mnogo više cene brzo urađen posao i prihvatljivu (minimalnu) cenu rada, nego provereni kvalitet (jer prevod, nije visoko na listi prioriteta poslodavaca), jeste jedan od vanjezičkih faktora za problematične prevode.

Pogrešno bi bilo zaključiti da u Kini nema odličnih prevodilaca koji vladaju engleskim jezikom, međutim oni rade važnije, kompleksnije i bolje plaćene poslove, tako da je ostavljeno mnogo prostora za amatersko bavljenje prevođenjem kada su u pitanju „manji poslovi“, poput natpisa u metroima, hotelima, restoranima, bolnicama, robnim kućama, parkovima, muzejima, na garderobi itd. To su, međutim, pojave koje stranci ne mogu a da ne primete kada stignu u Kinu i takvi prevodi ne ostavljaju dobru sliku o zemlji.

Svakako, primećuje se napor koji ulaže državna administracija da se u Kini, u javnom prostoru, nalaze adekvatni natpisi na engleskom jeziku. Ali, budući da ne postoji potpuna kontrola ko sve može da prevodi na engleski ili da ga 
predaje, verovatno će ovi prevodi turistima i strancima koji žive u Kini biti i dalje izvor zabave i deo „kineskog šarma“.

\section{LITERATURA}

Byrne Kate, "New Standard Translation Guide Heralds the End of 'Chinglish' in China", Junei27,i2017; https://theculturetrip.com/asia/china/articles/newstandard-transtation-guide-heralds-the-end-of-chinglish-in-china/ (Pristup: 21. 01.2020)

咸猪手 (奥港俗语), https://baike.baidu.com/item/咸猪手/355325 (Pristup: 01. 02. 2020)

Chinese grammar, https://www.chinese-grammar.org/lesson-21.html (Pristup: 17. 02. 2020)

Cummings Patrick J. and Wolf Hans-Georg. 2011. A dictionary of Hong Kong English. Words of the Fragrant Harbour. Hong Kong: Hong Kong University Press https://hkupress.hku/pro/con/526.pdf (Pristup: 17. 02. 2020)

Hui Du, "The globalisation of the English language: reflections on the teaching of English in China". International Education Journal Vol. 2, No 4, 2001, pp. 126-133. http://www.flinders.edju.au/education/iej/; (Pristup: 03. 03. 2020)

Zhang Yaying, "A Socio-Political View of English Language Teaching in the Chinese Context". English Language Teaching Vol. 1, No 2, December 2008, pp. 59-66. http://www.ccsenet.org/journal.html/; (Pristup: 03. 03. 2020)

Language $\log$, https://languagelog.ldc.upenn.edu/nll/?p=42301 (Pristup: 21. 01. 2020)

Urban Dictionary, https://www.urbandictionary.com (Pristup: 20. 01. 2020)

Wikipedia, https://en.wikipedia.org/wiki/Day_Day_Up (Pristup: 18. 01. 2020)

140 Most hilarious Chinese > English Translation Fails, https://www.actranslation.com/knowledge/fun/hilarious-translations.htm (Pristup: 20. 01. 2020)

\section{FOTOGRAFIJE}

Fotografija $\quad 1: \quad$ https://www.actranslation.com/knowledge/fun/hilarioustranslations.htm (Pristup: 20. 01. 2020)

Fotografija 2: https://languagelog.ldc.upenn.edu/nll/?p=9686 (Pristup: 20. 01. 2020)

Fotografije 3 i 4: Slikala autorka u Šangaju 15. 08. 2019.

Fotografija $5: \quad$ https://www.actranslation.com/knowledge/fun/hilarioustranslations.htm (Pristup: 20. 01. 2020.) 
Fotografija 6: http://www.bqb12.com/biaoqing/116196 (Pristup: 20. 08. 2019)

Fotografija 7: Slikala autorka u Šangaju 14. 08. 2019. godine.

Fotografija 8: http://www.jiaolgeji.com/zixun/6541.html (Pristup: 20. 08. 2019)

Fotografija 9: https://www.actranslation.com/knowledge/fun/hilarioustranslations.htm (Pristup: 20. 01. 2020.)

Fotografija 10: https://www.actranslation.com/knowledge/fun/hilarioustranslations.htm (Pristup: 20. 01. 2020).

Fotografija 11: Slikala autorka u hotelu Šeraton u Hangdžou 2018. godine

Fotografija 12: https://languagelog.ldc.upenn.edu/nll/?p=3978 (Pristup: 20. 08. 2019)

Darja P. Sekeruš Hoenn

\section{ANALYSE DES PROBLÈMES DE TRADUCTION DU CHINOIS À L'ANGLAIS DES INSCRIPTIONS DANS L'ESPACE PUBLIC}

\section{Résumé}

Les rues des villes chinoises sont pleines de nombreuses inscriptions en anglais qui suivent des informations utiles et des instructions pour les citoyens en chinois. Cependant, cette langue anglaise est loin de l'anglais standard. Ce fait a été remarqué par de nombreux touristes et étrangers vivant en Chine, qui souvent photographient au moins une de ces inscriptions en «anglais drôle». Ce sont des inscriptions que l'on peut trouver dans les métros, hôtels, restaurants, hôpitaux, grands magasins, parcs, musées, sur les vêtements. Ce phénomène est également très présent dans l'espace virtuel, dans les posts sur les réseaux sociaux, les blogs et les dépôts d'influenceurs chinois. Le document est une tentative d'analyse des causes des erreurs qui se produisent dans la traduction du chinois vers l'anglais des inscriptions dans l'espace publique. Outre les grandes différences dans la nature des deux langues, le manque de traducteurs professionnels et l'utilisation excessive de logiciels de traduction, qui ne s'accompagne pas d'une révision de traduction professionnelle, est une autre explication de ce phénomène. Après tout, de nombreuses inscriptions en anglais dans l'espace public en Chine ne sont pas destinées aux étrangers, mais "communiquent" avec la population locale et ont un caractère plus décoratif qu'informatif car elles créent l'illusion de l'internationalisation.

Mots clés: anglais, chinois, traduction automatique, espace public 